\title{
THE INCIDENCE OF AGENESIS OF PALMARIS LONGUS AMONG THE YORUBA TRIBE IN NIGERIA
}

\author{
Journal website at; \\ http://mrtbjournal.org/index.php/njmr/issue/current/showToc \\ GO Mbaka, AA Akinlolu, AO Ayanuga, PD Shallie, AK Adefule, HB Akpan, AB Ejiwunmi.
Department of Anatomy, Faculty of Basie Medical Sciences,
Olabisi Onabanjo University, P.M. B., 2002, Ago-Iwoye, Ogun State, Nigeria, \\ Correspondence to: \\ GOMbaka \\ mbaaka@yahoo.com
}

\begin{abstract}
SUMMARY
Background: Palmari longus (PL) has received a growing interest for its role in constructive surgery. Since the agenesis of PL showed strong racially variation, it was conceivable to investigate on Yoruba ethnic population in Nigeria.

Objective: To investigate the frequency of PL agenesis amongst the Yoruba population. The result obtained would be subjected to correlation analysis with the view to ascertaining the linearity between both limbs in the two sexes.

Materials and Methods: A total of 600 subjects comprising 335 males and 265 females aged 8-60years were used to assess the prevalence of agenesis of the PL in Yoruba tribe.
\end{abstract}

Results: The overall prevalence of absence was $6.7 \%$. In males, unilateral absence was $5.4 \%$. The distribution on the right and left were $2.4 \%$ and $3.0 \%$ respectively. The bilateral absence was $1.5 \%$. In females, unilateral absence was $6.0 \%$. The distribution on the right and left were $2.6 \%$ and $3.4 \%$ respectively. Bilaterally, it was $0.4 \%$.

In one subject unilaterally, PL was observed to have differentiated from flexor carpi radialis.

Conclusion: Results of this finding suggested that the prevalence of $\mathrm{PL}$ agenesis as reported in standard anatomy texts does not apply to Yoruba population. The consistency in higher prevalence of its agenesis amongst the Caucasian population in contrast to most Asians or blacks populations suggested that the incidence of $\mathrm{PL}$ absence is racially dependent.

Key Words: Palmaris longus; Agenesis; Yoruba tribe; Males; Females.

\section{INTRODUCTION}

Palmaris longus (PL) is a small vestigial musele that is phylogenetically degenerating. It is a slender musele that arises from the medial epicondyle by a common flexor tendon and from adjacent intermuscular septa. The characteristic of this muscle is shown by its short belly and long tendon (McMinn, 1997). The belly soon gives way to a long slender tendon of variable length (Ito et al, 2001) that inserts adherent across the front of flexor retinaculum to the palmar aponeurosis (Williams et al, 1989; McMinn, 1997; Palastanga et al, 1998).

This muscle is one of the most variable muscles in humans. The variations include duplication (digastrics) and the presence of accessory palmaris longus (Koo et al, 1997). The origin of this variation as illustrated by Humphrey (Kawashima et al, 2002), suggested the presence of radial, intermediate and ulnar sectors in the superficial layers of the forearm flexor muscular angulus. Thus PL usually differentiates from the intermediate sector but differentiation from the other two sectors may also be possible. It is also reported to develop independently from palmar aponeurosis and is associated oniy by anatomic proximity (Caughell et al, 1988).

PL, a weak flexor of the wrist is considered functionally negligible. However, there is a growing interest in the existence of the muscle because its tendon is reported to be most frequently harvested for reconstructive plastic and hand surgery (Sebastin et al, 2005). Besides, it had earlier been noted as a stabilizer of superficial structures in the palm in preparation to thumbs abduction (Fahrer, 1973; Fahrer and Tubiana, 1976).

The agenesis of PL has been reported in anatomy texts (Williams et al, 1989; McMinn, 1997; Palastanga, et al, 1998). The prevalence of the agenesis of this muscle as reported in most standard anatomy texts is about $15 \%$ (McMinn, 1997). A higher prevalence (24\%) was reported in North America Caucasians (Troha et al, 1990). A survey in Pennsylvania, USA showed $23 \%$ ineidence of absence (Wehbe, 1992). Ceyhan et al (1997) reported a higher prevalence of agenesis ( $25 \%$ ) in Gaziantep population in Turkey. Studies among the Asian population showed that 


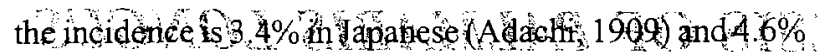
in Chinese (Sebastin et al 2005) respectively. Within Africa, studies have equally been conducted Avâulable information showed that the incidence is $1.02 \%$ in Ugandan population (Igbigbi, 1998).

The Yoruba tribe located in southwest Nigeria extends through Benin republic to Togo. It is the second largest ethnic group in Nigeria censtituting about $30 \%$ of her entire population. Their lives are structured around agriculture being the largest producer of cocoa in Nigeria, a major cash crop. They equally engage in tiâding and handicrafts (Olamijulo, 2004).

Since the incidence of agenesis reported in most anatomy texts represent Caucasian populations, we think it will be informative to report on the prevalence of this muscle in Yoruba population, southwest, Nigeria.

\section{MATERIALSAND METHODS}

Subjects: A total of 600 subjects comprising 335 males and 265 females aged 8-60 years were used to assess the prevatence of agenesis of PE. If was believed that within this age bracket, the subjects would be abie to thanoeivite their fiands to conform to the firtistetion. The? subjects were selected froth anothgst mernbers of the university community, primary âna secondary schoobls and ibusiness

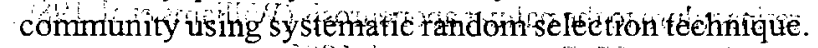

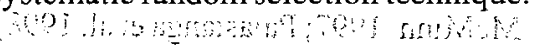

Materlals Instrumentation: The exereise was conducted with four different inethods of assessments which has been field validated a ald dre known to be reliable techniques for PL assessment (Sebastin et al, 2006). These include; standard test (Schaeffer's test); Thonpson's tést, Mishura's

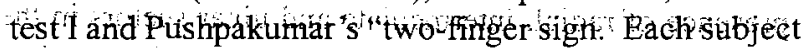
was fnitialty asked to do the standard test, where the technique was hot siffriently manoediveded, either

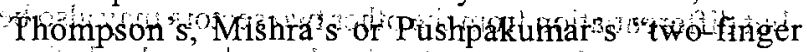
sign" tests and tr sóme situations the three were used for retest: The use of aniy of these tests was how wever thot in any particular sequence

Ethical apprótal was sought and obtained from the schools used and with the coloperation of the teachers "maniy to ré enthusiastie for the exercise. Also, those that consented among the business class were used The investigation was carrfed out amongst subjects that both

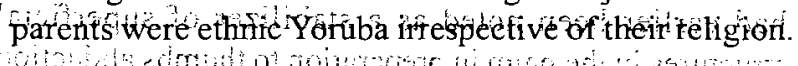

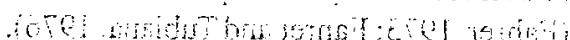

Procedure: The execcise wâs conducted with the subjects in the standing position. In Schaeffer's test, subjects were made te steady the ir forearm at 90 before opposing the thumb to the little finger with the wrist partially flexed. In Thompson's test, a fist was made followed by flexing the wrist against resistance with the thumb flexed over the fingers. In Mishra's test I, the subjects were asked to abduct the thumb against resistance with the wrist partially flexed. In Pushpakumar's "two-finger sign" method, the subjects were made to fully extend the index and middle finger while the wrist and other fingers were fully flexed with the thumb opposed and flexed.

Statistical analysis: The incidence of agenesis of this muscle in both sexes and on the two sides of upper limbs Was analyzed using SPSS. Correlation and percentage score were used to assess the association of its agenesis in both sexes unilaterally and bilaterally. The percentage score besides being the more conventional assessment technique was less technical. However, the inclusion of correlation coefficient was to determine the linearity of agenesta between both linbs and in the two sexes.

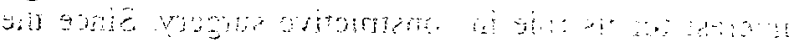
RESULTS

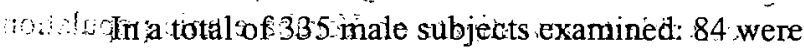
primary school pupils (below 12 years); 95 were secondary schol students (12+16 years);:112 university students (17-29years) white 4 were from the basiness community

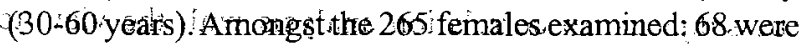
primbiry schól puphits (belowil2years); 89 were secondary school students (12-16 years); 91 were university students (17-29 years) while wit wetre from the business community (30) 60 years)

tist The overall prevalence of absence was $6.7 \%:(40$ subjects) (Table 1). In males, PL was found to be absent unilaterally in 18 subjects $(5,4 \%)$, the distribution on the right and leff were $8(2.4 \%)$ and $10(3.0 \%)$ respectively. B laterally (Table 2), this musele was absent in 5 subjects $(-1: 5 \%$. The overalt prevalence of absence in males was $6.9 \%$ (23) In females, AL was absènt unitaterally in 16 subjects $(6.0 \%)$, the distributions on the kight and left were 7 ( $2.6 \%)$ and $9(3.4 \%)$ respeotively. Bilaterally (Table 2), it was $1(0.4 \%)$;ithe overall prevalence of absencé for

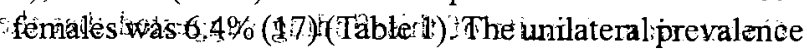
of absence between ther mates and femáles showed no

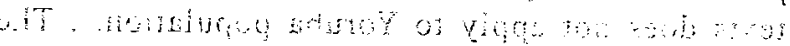

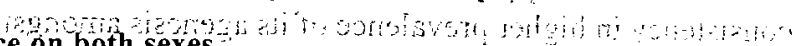
Table 1 The distribution of palmaris longus absence on both sexes

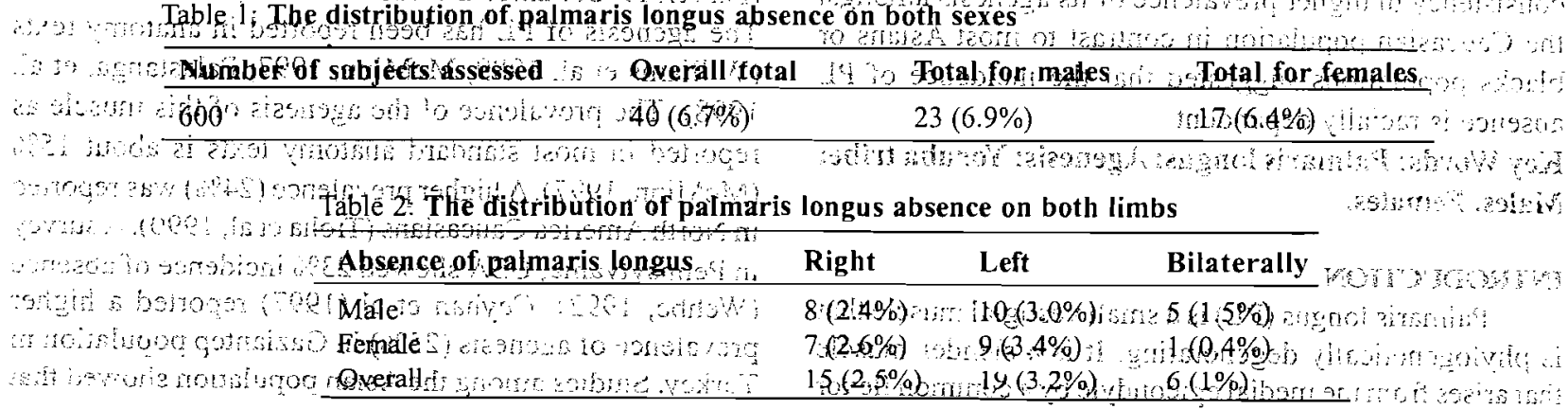


Table 3: Correlation coefficient of palmaris longus absence

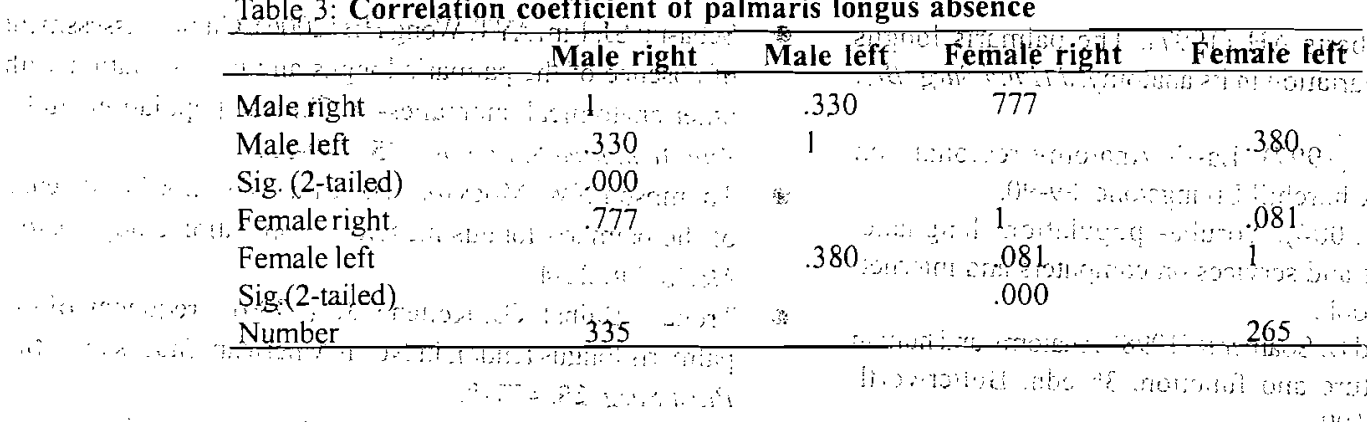

significant difference $(\mathrm{P}<0.05)$ (Table 2$)$. However, bilateral prevalence of absence in males was comparatively higher than infemales:

The correlation analysis showed (Table 3 ) that the agenesis on males right was strongly correlated to the males left with linearity of 1 to $0.330(\mathrm{P}<0.01)$. On the contrary, the assessment of the two females limbs indicated weak correlation $\{1$ to $0.081(\mathrm{P}<0.01)\}$. However, the interclass assessment of males' right and females' right agenesis was observed to be most strongly correlated with 1 to $0.777(\mathrm{P}<0.01)$

\section{DISCUSSION}

The findings on Yoruba ethnic population showed an overall prevalence of absence of PL to be $6.7 \%$. This observation differs markedly with most reports in standard anatomy texts (15\%) believed to represent Caucasian population. This assumption is strengthened by a similar high prevalence of absence $(24.4 \%)$ reported in North American Caucasians (Troha et al, 1990); Pennsylvania (23\%; Wehbe, 1992) and on Germans (20.4\%; Gruber, 1872). However, our observation tallied with the reports on Asian population which according to Adachi (1909) and Sebastin et al, (2005) were $3.4 \%$ and $4.6 \%$ for Japanese and Chinese respectively but differed with the report of recent survey on Indian population of $17.2 \%$ (Kapoor et al, 2008). A black population report on Ugandans subjects (Igbigbi and Ssekitoleko, 1998) showed much lower result of $1.02 \%$ This is indicative of strong racial dependent agenesis of the muscle.

The unilateral absence observed to be higher in females (6.0) than in males $(5.4 \%)$ correlated with most previous reports (Troha et al, 1990; Ceyhan et al, 1997) except for the report on Ugandans (Igbigbi and Ssekitoleko, 1998). The difference between the unilateral and bilateral absence of the muscles was marked. The much lower incidence observed bilaterally is consistent with other accounts (Thompson et al, 2001; Sebastin et al, 2005) but differed markedly with Ceyhan et al, (1997) report on Gaziantep population. There was no significant difference in the unilateral absence in both sexes. But bilaterally, the difference was marked. A strong correlation of agenesis was observed particularly between the interclass assessment of male right and the female right.

\section{CONCLUSION}

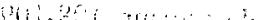
- in we conclude from these results that there to incidence of abserice of PL among the roba in Southwest Nigeria: ft is clear from standard prevalence of agenesis of PL that the report does not apply to Yoruba population. The consistency in higher prevalence of its agenesis amongst the Caucasian population in contrast to most Asians or blacks populations suggested that the incidence of PL absence is racially dependent. Furthermore, this finding showed strong association of PL agenesis in both limbs of males and females.

\section{REFERENCES}

- Adachi B (1909). Beitrage zur anatomie der Japaner. Die statistic der muskel varietaben zweite mitteiloung. Zeitsch folia morphologie der anthropologie. 12: 261-312.

- Caughell KA, McFarlane RM, McGrouther D, Martin AH (1988). Developmental anatomy of the palmar aponeurosis and its relationship to the palmaris longus tendon. $J$ Hand $\operatorname{surg}(\mathrm{Am})$. 13: 485-95.

- Ceyhan O and Mavt A (1997). Distribution of agenesis of paimaris longus muscle in 12 to 15 years old age groups. Indian J Med Sci. 51: 156-60.

- Fahrer M(1973). The role of palmaris longus muscle in the abduction of the thumb. J. Anat. 116: 476.

- Fahrer M, Tubiana R (1976). Anteductor of the thumb. Hand. 8: $287-9$.

- Gruber W (1872). Beobachten aus der Menschlcher Und Vergleichendan Anatomie Berlin. Memories de l'Academic Imperiale de St. Petersburg. 11: 1-26.

- Igbigbi PS and Ssekitoleko HA (1998). Incidence of agenesis of the palmaris longus muscle in Ugandans. West African Journal of Anatomy. 6:21-23.

- Ito M M, Aoki M, Kida M Y, Ishii S, Kumaki K, Tanaka S (2001). Length and Width of the tendinous portion of the palmaris longus : a cadaver study of adult Japanese. $J$ Hand Surg (Am). 26: 706-10.

- Kapoor SK, Tiwari A, Kumar A, Bhatia R, Tantuway V, Kapoor S (2008). Clinical relevance of palmaris longus agenesis: common anatomical aberration. Anat. Sci Int. 83 45.48.

- Kawashima T, Kikushima S, Hokota E, Ohkubo F, Yamana Y, Sato F, Sasaki H (2002) A case of an accessory palmaris longus muscle and a duplicate palmaris longus muscle with special reference to their nerve supply-morphologic significance of a common innervation trunk. Okajimas Folia Anat Jpn. 79: 75-81. 
- Koo CC and Roberts AH (1997). The palmaris longus tendon. Another variation in its anatomy. $J$ Hand Surg $(B r)$. 22: 138-9.

- McMinn R M H (1997). Last's Anatomy regional and applied. 9th edn. Churchill Livingstone. 89-90.

- Olamijulo, SK (2004). Yoruba- population, language, projects, products and services on computers and internet. CIA World Factbook.

- Palastanga N, Field D, Soamer R(1998). Anatomy and human movement structure and function. $3^{\text {rd }}$ edn. Butterworth Heinemann. 108-109.

- Sebastin SJ, Puhaindran ME, Lim AY, Lim IJ, Bee WH (2005). The prevalence of absence of the palmaris longus A study in a Chinese population and a Review of the Literature. $J$ Hand Surg (Br). 30: 525-527.
- Sebastin SJ, Lim AYT, Wong HB (2006). Clinical assessment of absence of the palmaris longus and its association with other anatomical anomalies- A Chinese population study. Ann Acad Med Singapore. 35: 249-53.

- Thompson NW, Mockford BJ, Cran GW (2001). Absence of the palmaris longus muscle: a population study. Ulster Med J. 70: 22-4.

- Troha F, Baibak GJ, Kelleher JC (1990). Frequency of the palmaris longus tendon in North American Caucasians. $A n n$ Plast Surg. 25: 477-8

- Wehbe MA (1992).Tendon graft donor sites. J Hand Surg (Am). 17: 1130-2.

- Williams PL. Warwick R, Dyson M, Bannister LH (1993). Gray's Anatomy. $37^{\text {th }}$ edn. Churchill Livingstone, 617. 